\title{
The Impact of COVID-19 Infection on Macular Capillary Perfusion
}

mine esen baris ( $\square$ mine.baris@yahoo.com )

Ege Universitesi Tip Fakultesi https://orcid.org/0000-0003-1341-6737

Cumali Degirmenci

Ege University Faculty of Medicine: Ege Universitesi Tip Fakultesi

Suzan Guven Yilmaz

Ege University Faculty of Medicine: Ege Universitesi Tip Fakultesi

Filiz Afrashi

Ege University Faculty of Medicine: Ege Universitesi Tip Fakultesi

Husnu Pullukcu

Ege University Faculty of Medicine: Ege Universitesi Tip Fakultesi

Meltem Tasbakan

Ege University Faculty of Medicine: Ege Universitesi Tip Fakultesi

\section{Research Article}

Keywords: COVID-19, optical coherence tomography angiography, retinal capillary perfusion

Posted Date: January 11th, 2022

DOI: https://doi.org/10.21203/rs.3.rs-1231965/v1

License: (c) (1) This work is licensed under a Creative Commons Attribution 4.0 International License. Read Full License 


\section{Abstract}

Purpose: To evaluate the impact of a prior non-severe COVID-19 infection on retinal microcirculation with optical coherence tomography angiography (OCTA).

\section{Methods:}

A total of 83 eyes of 43 patients with a history of non-severe COVID-19 infection confirmed with a positive PCR test (Group 1) and 30 age-matched healthy controls (Group 2) underwent detailed eye examination including Spectral-Domain OCT (Topcon-Triton Swept Source) and OCTA (RTVue-XR Avanti) scanning. OCTA images $(6 \times 6 \mathrm{~mm})$ images were used to assess vessel densities (VD) in superficial capillary plexus (SCP) and deep capillary plexus (DCP) and foveal avascular zone (FAZ).

\section{Results:}

The mean duration between the COVID-19 positive PCR test and ocular examination was $144.6 \pm 82.2$ days (range: $30-270$ ). VD of SCP and DCP in the foveal and perifoveal regions were significantly lower in Group 1 compared to Group $2(p<0.05)$.

\section{Conclusion:}

Non-severe COVID-19 infection may cause a decrease in VD of retinal SCP and DCP.

\section{Introduction}

Since the beginning of the COVID-19 pandemic, hyper-coagulability and thromboembolic complications related to the SARS-CoV-2 infection have been frequently reported. Patients with severe COVID-19 are particularly susceptible to pneumonia and sepsis induced coagulopathy, which may progress to disseminated intravascular coagulation with increased D-dimer and fibrin degradation products, if left untreated. ${ }^{1}$ Retinal capillaries are common sites for thromboembolic complications in many systemic diseases with hyper-coagulation. While thromboembolic complications of COVID-19 infection mainly consist of deep venous thromboembolism, pulmonary embolism or myocardial infarction, there are also reports of retinal venous, even arterial occlusions associated with this infection. ${ }^{2-6}$

Optical coherence tomography angiography (OCTA) is a new, non-invasive and rapid technique that allows the quantitative evaluation of retinal capillary perfusion by automatically calculating vessel densities of retinal superficial and deep capillary plexuses.

Herein, using OCTA we aimed to investigate whether complication free COVID-19 infection has any impact on macular capillary perfusion in patients who have recovered from non-severe COVID-19.

\section{Materials And Methods}

This cross-sectional, observational study was conducted between March 2020-April 2021 at Ege University Hospital, İzmir, Turkey. A total of 73 patients were included in the study and participants were separated in two groups. Inclusion criteria for Group 1 were the following: 1. Being a health care professional working in Ege University Hospital 2. Having a medical history of non-severe and/or asymptomatic COVID-19 infection confirmed with positive PCR tests from nasopharyngeal swabs. Inclusion criteria for Group 2 were: 1 . Being a health care professional at the same hospital, 2. No history of any systemic or ocular disease, 3. Not having a history of COVID-19 infection or any contact with someone who had the infection (including under professional circumstances). Group 1 consisted of 43 (58.9\%) individuals while Group 2 consisted of 30 (41.1\%) age-matched healthy controls. Exclusion criteria for Group 1 included the presence of COVID-19 related complications (such as thromboembolic complications, need for oxygen support, high grade fever etc.) or hospitalizations (including emergency service applications) and presence of any systemic or ocular diseases.

All patients included in the study underwent a detailed ophthalmological examination that was performed by the same ophthalmologist. The examination included best corrected visual acuity (BCVA) with Snellen chart, measurement of intraocular pressure (IOP) with Goldmann applanation tonometer, biomicroscopic anterior segment examination and posterior segment examination with 90D lens. Spectral-domain optical coherence tomography (OCT, Topcon, Triton Swept Source, Tokyo, Japan) and OCT angiography (OCTA, Optovue, RTVue-XR Avanti, CA, USA) scans were obtained for all participants.

The age and gender of the patients, the duration between the ophthalmological examination and positive PCR tests as well as their symptoms and medications used during the infection were noted. BCVA values were converted to LogMAR for statistical analyses. Subfoveal choroidal thickness (SFCT) was measured from the OCT scans ( $6 \times 6 \mathrm{~mm}$, HD Raster) manually.

The OCTA analysis divided the macular area ( $6 \times 6 \mathrm{~mm}$ quadrant centered on the fovea) into the whole image, foveal, parafoveal and perifoveal regions and then automatically calculated the vessel densities (VD) of superficial capillary plexus (SCP) and deep capillary plexus (DCP). The foveal avascular zone (FAZ) was also automatically calculated by the OCTA system. Scans were assessed for flow area of choriocapillaris and outer retina at 1 mm radius, FAZ, central retinal thickness (CRT) and VD in the SCP and DCP.

All OCT and OCTA examinations were performed by the same technician (NA). Eyes with low quality OCTA images (7/10 and higher were accepted as good quality) due to dense cataract or high refractive errors were excluded from the study. All OCTA and OCT images were examined by the same ophthalmologist (MEB). 
Informed consent was obtained from all study participants and institutional review board approval was gathered from the Ege University Medical Studies Ethical Committee (Approval number: 20-8.1T/37). The study was conducted in accordance with the tenets of Declaration of Helsinki.

\section{Statistical Analysis}

Statistical analysis was performed using SPSS software (Version 20; SPSS Inc., Chicago, Illinois, USA). All data are reported as mean \pm Standard deviation (SD) and demographic data were compared with Chi Square test. Independent t test was used to compare data between groups with normal distribution while Mann Whitney U test was used for data without normal distribution. P values less than 0.05 was considered to be statistically significant.

\section{Results}

A total of 83 eyes of 43 patients (29 (67.4\%) female, 14 (32.6\%) male) assigned to Group 1 and 60 eyes of 30 patients (15 (50\%) female, 15 (50\%) male) assigned to Group 2 were included in the study. Both eyes of all patients were included with the exception of 3 patients in Group 1 . Only one eye of each of those 3 patients were included due to low image quality of OCTA obtained from the other eye. The reason for low quality of imaging were keratoplasty in 1 eye, cataract in 1 eye and corneal scar in 1 eye. The mean age was $40.29 \pm 10.08$ (range, 24-70) years in Group 1 and $40.36 \pm 8.67$ (range, $31-53$ ) years in Group $2(p=0.2)$. All the eyes included in the study had a BCVA of 20/20 (0 LogMAR) and none of them had high refractive errors (cylinder correction range was -1.50 to +1.00 ; spherical correction range was \pm 3.50 ). There were no significant differences in BCVA and refractive errors between the groups $(p=1.9$ and $p=1.5$, respectively). The demographics of two the groups and the symptoms of the patients in Group 1 during the acute phase of SARS-CoV-2 infection are summarized in Table 1.

Table 1

The demographics of study participants and The symptoms of patients in Group 1 during the acute phase of the infection

\begin{tabular}{|c|c|c|c|}
\hline & $\begin{array}{l}\text { Group } 1 \\
\text { (COVID-19 Group) }\end{array}$ & $\begin{array}{l}\text { Group } 2 \\
\text { (Control Group) }\end{array}$ & $P$ value \\
\hline \multicolumn{4}{|l|}{ Demographics } \\
\hline Number of patients, $\mathrm{n}(\%)$ & $43(58.9)$ & $30(41.1)$ & \\
\hline Mean age $\pm S D$ & $40.29 \pm 10.08$ & $40.36 \pm 8.67$ & $0.2^{\star}$ \\
\hline Gender & $29(67.4)$ & $19(63.3)$ & $1.2^{\star \star}$ \\
\hline Female, n (\%) & $14(32.6)$ & $11(36.6)$ & \\
\hline \multicolumn{4}{|l|}{ Male, n (\%) } \\
\hline \multicolumn{4}{|l|}{ Symptoms, n(\%) } \\
\hline Fever $\left(<39.0^{\circ} \mathrm{C}\right)$ & $4(9.3)$ & - & \\
\hline Headache & $16(37.2)$ & - & \\
\hline Myalgia & $24(55.8)$ & - & \\
\hline Anosmia & $25(58.1)$ & - & \\
\hline Cough & $5(11.6)$ & - & \\
\hline Asymptomatic & $18(41.8)$ & - & \\
\hline \multicolumn{4}{|l|}{ *Independent samples $t$ test } \\
\hline
\end{tabular}

Biomicroscopic anterior segment examination revealed that 4 eyes in Group 1 and 2 eyes in Group 2 had Grade 1 nuclear sclerosis. No other anterior segment pathologies were observed. Fundus examinations were also normal in all patients in both groups; no lesions were detected.

No statistically significant differences could be identified in SFCT $(310.5 \pm 161.7 \mu \mathrm{m}$ vs $298.9 \pm 165.0 \mu \mathrm{m} ; \mathrm{p}=0.7)$ and CRT (249.2 $\pm 19.3 \mu \mathrm{m}$ vs $253.1 \pm 15.9 \mu \mathrm{m}$; $\mathrm{p}=0.3)$ between Group 1 and Group 2. Mean outer retinal flow area also showed no significant difference in between the two groups $\left(0.62 \pm 0.4 \mathrm{~mm}^{2}\right.$ vs $0.7 \pm 0.3$ $\left.\mathrm{mm}^{2} ; \mathrm{p}=0.3\right)$. The mean choriocapillaris flow area was significantly larger in Group $1\left(2.14 \pm 0.1 \mathrm{~mm}^{2}\right)$, compared to Group $2\left(2.04 \pm 0.2 \mathrm{~mm}{ }^{2} ; \mathrm{p}=0.01\right)$.

FAZ was significantly larger in Group $1(0.29 \pm 0.12)$ compared to Group $2(0.24 \pm 0.07 ; p=0.01)$. VD of the deeper capillary plexus (DCP) in the whole image was significantly lower in Group 1 than Group $2(54.8 \pm 6.4 \%$ vs $58.9 \pm 4.3 \% ; p=0.01)$, the same was observed in superior $(54.5 \pm 6.7 \%$ vs $58.6 \pm 4 \%$; $p=0.02)$ and inferior $(55.0 \pm 6.5 \%$ vs $59.2 \pm 5.2 \% ; p=0.01)$ hemi-retinal quadrants as well as the foveal $(42.1 \pm 6.1 \%$ vs $57.8 \pm 5.8 \%$; $p=0.02)$ and perifoveal $(51.1 \pm 6.6 \%$ vs $53.6 \pm 3.3 \%$; $\mathrm{p}<0.01)$ regions. VD of DCP in the parafoveal region was slightly lower in Group 1 compared to Group $2(57.8 \pm 5.8$ vs $59.9 \pm 4.5)$, but the difference did not reach statistical significance $(p=0.06)$.

VD of superficial capillary plexus (SCP) in the whole image area ( $5.0 \pm 3.4 \%$ vs $53.0 \pm 3.5 \%)$, superior $(51.0 \pm 3.4 \%$ vs $52.9 \pm 3.4 \%)$ and inferior $(51.1 \pm 3.7 \%$ vs $53.1 \pm 3.7 \%)$ hemi-retinal quadrants, and the foveal $(20.7 \pm 9.1 \%$ vs $24.6 \pm 6.6 \%)$ and perifoveal $(51.1 \pm 6.6 \%$ vs $53.6 \pm 3.3 \%)$ regions were significantly lower in 
Group 1, compared to Group 2. VD of SCP in the parafoveal region was slightly lower in Group 1 compared to Group 2 but difference was not statistically significant $(p=0.07)$. The OCT and OCTA findings and the $p$ values are summarized in Table 2.

Table 2

OCT and OCTA parameters of COVID-19 patients (Group 1) and healthy controls (Group 2)

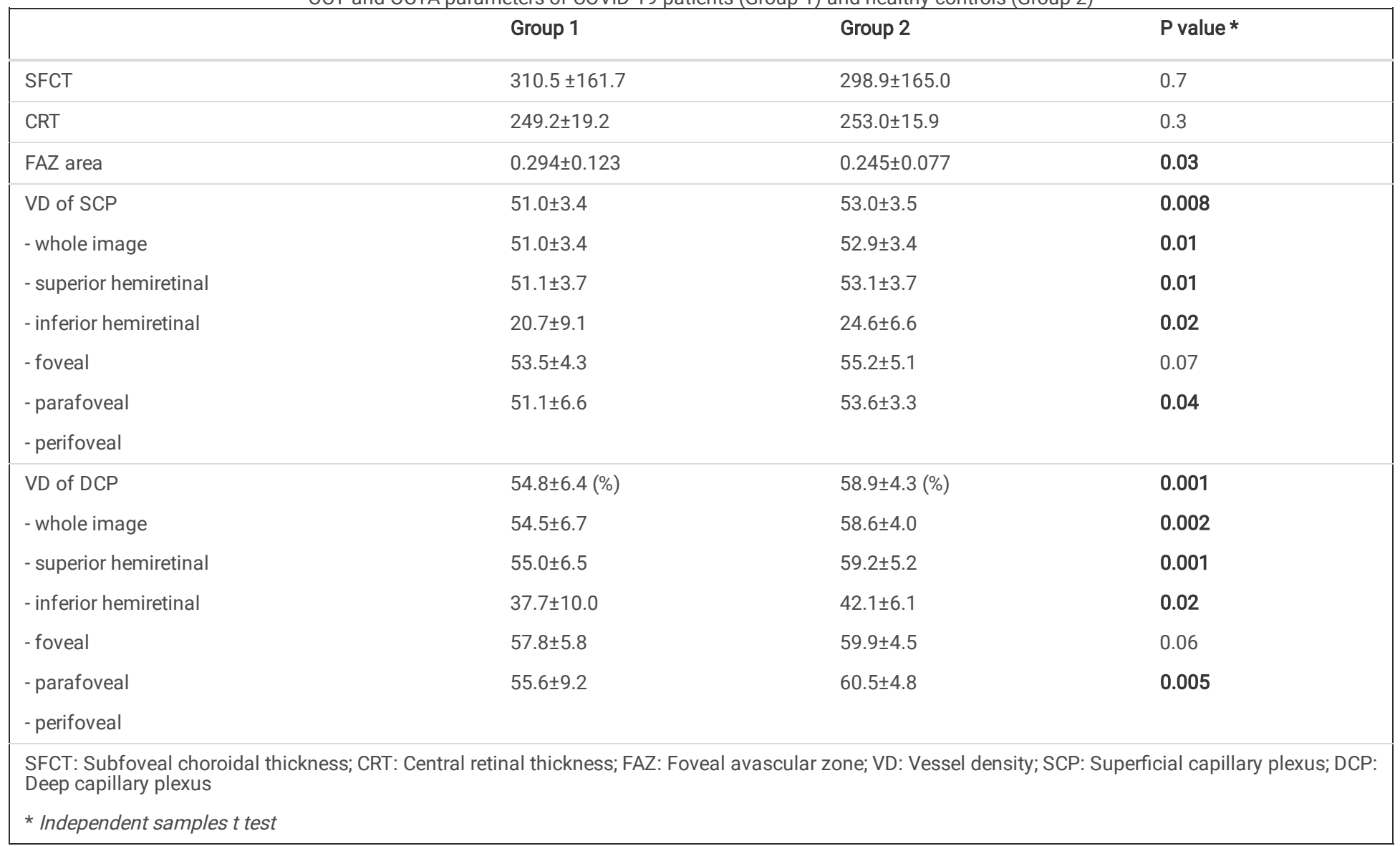

The mean duration since the first positive PCR test for SARS-CoV-2 and the ocular examination was 144.6 \pm 82.2 days (range: $30-270$ days). All patients in Group 1 received $100 \mathrm{mg}$ acetyl salicylic acid, once daily for 1 month. As an antiviral treatment, all patients received favipiravir $1.8 \mathrm{mg}$ twice daily on day 1 , then $600 \mathrm{mg}$ twice daily for 14 days, as per local health care guidelines.

Patients in Group 1 were also investigated for the effect of gender and the duration between the positive PCR test and the day of examination on the ocular findings. There were no significant differences in VD and FAZ as a function of gender; however, CRT was significantly lower in females compared to males. No correlations were observed between the duration since the SARS-CoV-2 infection and VD of DCP and SCP, in any region.

Since the study participants were chosen from health care professionals working at a University hospital, OCTA images of 9 eyes of 5 patients in Group 1 were already present in the database of the hospital. Therefore, we were able to compare the pre-COVID-19 and post-COVID-19 OCTA images captured with the same device. The mean duration between the two OCTA images were $26 \pm 8.4$ months (range: 18-40). VD of SCP was reduced in 5 ( $55.5 \%$ ) eyes in the whole image, superior hemiretinal and inferior hemiretinal quadrants; the same was reduced in $4(44.4 \%)$ eyes in the foveal, parafoveal and perifoveal regions. VD of DCP was decreased in 4 (44.4\%) eyes in the whole image, superior hemiretinal and inferior hemiretinal quadrants, in 1 (11.1\%) eye in foveal region, in 2 eyes $(22.2 \%)$ in parafoveal region and in $4(44.4 \%)$ eyes in perifoveal region. The pre- and post COVID-19 data on VD of SCP and DCP of the 10 eyes are summarized in Table 3. The low sample size precluded any reliable statistical analyses. 
Table 3

Vessel Densities of superficial capillary plexus and deep capillary plexus before and after the COVID-19 iI

\begin{tabular}{|c|c|c|c|c|c|c|c|c|c|c|c|c|c|c|c|c|c|c|c|c|}
\hline \multirow{3}{*}{$\begin{array}{l}\text { P. } \\
\text { No }\end{array}$} & \multirow[t]{3}{*}{ A } & \multirow[t]{3}{*}{ G } & \multirow[t]{3}{*}{ Eye } & \multicolumn{12}{|c|}{ VD of SCP } & \multicolumn{5}{|c|}{ VD of DCP } \\
\hline & & & & \multicolumn{2}{|c|}{$\begin{array}{l}\text { Whole } \\
\text { image }\end{array}$} & \multicolumn{2}{|c|}{$\begin{array}{l}\text { Superior } \\
\text { hemiretinal }\end{array}$} & \multicolumn{2}{|c|}{$\begin{array}{l}\text { Inferior } \\
\text { hemiretinal }\end{array}$} & \multicolumn{2}{|c|}{ Foveal } & \multicolumn{2}{|c|}{ Parafoveal } & \multicolumn{2}{|c|}{ Perifoveal } & \multicolumn{2}{|c|}{$\begin{array}{l}\text { Whole } \\
\text { image }\end{array}$} & $\begin{array}{l}\text { Superior } \\
\text { hemiretinal }\end{array}$ & \multicolumn{2}{|c|}{$\begin{array}{l}\text { Inferic } \\
\text { hemir }\end{array}$} \\
\hline & & & & Pre- & Post- & Pre- & Post- & Pre- & Post- & Pre- & Post- & Pre- & Post- & Pre & Post & Pre- & Post- & Pre- & Post- & $\mathbf{P}$ \\
\hline \multirow[t]{2}{*}{1} & 30 & $\mathrm{~F}$ & $\mathrm{R}$ & 48.2 & 46.3 & 47.8 & 46.1 & 48.7 & 46.4 & 18 & 17.9 & 49.2 & 51.2 & 48.3 & 47.2 & 43.4 & 59.9 & 42.8 & 59 & 4 \\
\hline & & & L & 46.7 & 50.9 & 46.5 & 50.3 & 46.9 & 51.6 & 17.5 & 23.2 & 46.2 & 51.6 & 47.8 & 51.7 & 50 & 59.2 & 50.3 & 59.2 & $4^{\prime}$ \\
\hline \multirow[t]{2}{*}{2} & 33 & M & $\mathrm{R}$ & 56.1 & 51.9 & 56.2 & 51.3 & 55.9 & 52 & 26.3 & 21.9 & 57.2 & 50.2 & 57 & 52.7 & 56.7 & 53 & 56.6 & 53.9 & 51 \\
\hline & & & L & 58.9 & 54.7 & 59 & 54.5 & 58.8 & 55 & 26.7 & 21.6 & 61.3 & 56.6 & 60.6 & 56.4 & 59.8 & 56.5 & 59.3 & 56.5 & 61 \\
\hline 3 & 31 & M & $\mathrm{R}$ & 54.2 & 52.3 & 53.8 & 51.7 & 54.6 & 52.9 & 23.8 & 23.1 & 57 & 56.2 & 54.7 & 52.7 & 60.6 & 58 & 59.2 & 56.6 & 6: \\
\hline \multirow[t]{2}{*}{4} & 50 & $F$ & $\mathrm{R}$ & 50.1 & 52.2 & 50.2 & 51.8 & 50.1 & 52.6 & 12.8 & 16.5 & 51.6 & 53.8 & 50.4 & 53.4 & 57.5 & 60.7 & 58.9 & 59,8 & 51 \\
\hline & & & L & 54.6 & 51.2 & 53.8 & 51.0 & 55.3 & 51.4 & 20.9 & 14.5 & 56.3 & 52.8 & 55.4 & 51.9 & 59.3 & 63.8 & 58.9 & 63.5 & $5^{\prime}$ \\
\hline \multirow[t]{2}{*}{5} & 48 & $F$ & $\mathrm{R}$ & 54 & 53.9 & 53.3 & 52.4 & 54.6 & 55.4 & 20.8 & 28.2 & 55.8 & 55.9 & 54.7 & 54.0 & 57.5 & 57.7 & 54.9 & 55.3 & 61 \\
\hline & & & L & 55.1 & 55.2 & 54.6 & 54.7 & 55.4 & 55.6 & 26.3 & 27.3 & 58 & 57.5 & 56.1 & 56.3 & 60 & 57.8 & 60 & 58.2 & 61 \\
\hline
\end{tabular}

P: Patient; A: Age; G: Gender; VD: Vessen Density; SCP: Superficial capillary plexus; DCP: Deep capillary plexus; F: Female; M: Male

\section{Discussion}

Thromboembolic complications of SARS-CoV-2 infection are a major problem, especially in severe cases. Pulmonary embolism is the most common thromboembolic complication related to SARS-CoV-2 infection and it is also one of the causes of mortality. In severe cases, the prevalence of pulmonary embolism is reported as $2.6 \%$, the prevalence of stroke is reported to be up to $3 \%$ and venous thromboembolism is reported to be up to $20 \%$. ${ }^{7,8} \mathrm{Herein}$, we investigated the impact of non-severe SARS-CoV-2 infection on retinal microcirculation by OCTA, $144.6 \pm 82.2$ days after the first positive PCR test.

The study group (Group 1) and control group (Group 2) were age and sex matched and revealed no significant differences in BCVA and refractive errors. Corroborating these data, Costa et al. ${ }^{9}$ did not report any significant difference in the prevalence of myopia and hyperopia among infected and non-infected individuals, compared to prevalence studies in the general population.

Regarding the anterior segment findings, Costa et al. ${ }^{9}$ reported the presence of cataracts in two eyes with the diagnosis known before the infection; no other pathologies or signs of uveitis were observed. In the current study, cataract was the only anterior segment change detected in both groups; additionally, there was no significant difference in the incidence of cataracts between the groups.

In the current study, intraocular pressure measurements were similar in both groups. Costa et al. ${ }^{9}$ reported a modest but statistically significant higher IOP in critical COVID-19 patients compared to severe and moderate cases (approximately $14.00 \mathrm{mmHg}$ vs $12.00 \mathrm{mmHg}$ ). However, a large proportion of patients with critical infection received systemic corticosteroid treatment (48\% of the cases evaluated), ${ }^{9}$ potentially leading to such a low difference in IOP.

None of the eyes evaluated in the current study showed any pathologies in fundus evaluation in both groups. Since none of the participants in the study or control groups had any systemic diseases, this was foreseeable. Bypareddy et al ${ }^{10}$ also reported the lack of any fundus pathologies in non-severe COVID-19 patients, except a single streak of retinal hemorrhage in one eye. Costa et $\mathrm{al}^{9}$ reported the frequency of diabetic retinopathy as $52.7 \%$. As mentioned previously, all of our cases had a history of non-severe COVID-19 infection and none of them had any chronic diseases such as diabetes or hypertension. Costa et al ${ }^{9}$ reported the presence of yellowish-white dots in the outer retinal layers in two patients, both of whom had critical disease. ${ }^{99}$ Zago Filho et al $^{11}$ also previously reported yellowish-white lesions in macular area of a COVID-19 patient in both eyes; however, these lesions were located in posterior hyaloid surface, inner plexiform and ganglion cell layers.

We observed significantly lower macular vessel densities of both SCP and DCP in all quadrants, except for parafoveal region in Group 1 (recovered non-severe COVID-19 patients) compared to Group 2 (healthy controls). In parafoveal regions of SCP and DCP, VD was slightly lower in Group 1 compared to Group 2; this difference approached but did not reach statistical significance ( $p=0.07$ for SCP and $p=0.06$ for DCP). None of the patients in the current study were hospitalized during the acute phase of the infection and many of them were asymptomatic (41.8\%). Guemez-Villahos et al ${ }^{12}$ also reported that VD was reduced in COVID-19 patients compared to healthy controls. The same study also reported that COVID-19 patients with and without thromboembolic events related to infection did not show any significant difference in VD. Interestingly, Turker et $\mathrm{al}^{13}$ reported that VD was significantly lower in the parafoveal region of COVID-19 patients compared to controls, but the foveal region was not reported to be affected. Of note, the study included patients who were hospitalized during the acute phase of the infection, which suggests the presence of moderate or severe disease. Cennamo et al ${ }^{14}$ reported that VD was significantly lower in both foveal and parafoveal regions of SCP and DCP. This study also included patients who were hospitalized for COVID-19 pneumonia, which again might indicate a moderate to severe infection. 
The parafoveal region was found to be either not affected or the least affected in the current study, while the foveal and perifoveal regions were found to be significantly affected. The parafoveal region is richest in VD of SCP and DCP, therefore it is likely to be relatively better preserved. ${ }^{15,16}$ The choriocapillaris flow area was significantly larger in COVID-19 patients in the current study, similar to other studies in the literature. ${ }^{13}$

In the current study, all patients were evaluated after a mean duration of $144.6 \pm 82.2$ days (range, $30-270$ days) of the acute phase of the infection and a positive PCR test. In statistical analysis, we did not observe any correlations between VD of SCP or DCP and the duration from SARS-CoV-2 infection to ocular examination. This suggests that the impact of COVID-19 on macular capillary perfusion might be permanent. To the best of our knowledge, this is the first study to investigate this correlation.

SARS-CoV-2 infection causes immune dysfunction and vascular endothelial injury, resulting in systemic microangiopathy. SARS-CoV-2 related inflammation was thought to be the primary cause of endothelial dysfunction; however, studies suggest that endothelial cells lack ACE2 expression, which is required for the virus to infect a cell directly. ${ }^{17,18}$ On the other hand, studies also indicate that the virus itself can directly infect endothelial cells in the lungs. ${ }^{19,20}$ More recent studies have shown that SARS-CoV-2 can directly infect mature vascular endothelial cells both in vivo and ex vivo. ${ }^{21}$ It was also reported that infection with SARS-CoV-2 can lead to the degradation of the glycocalyx, the protective layer of vascular endothelial cells, and causes increased levels of hyaluronan a major component of glycocalyx in the systemic circulation. ${ }^{22}$ Significant damage of the glycocalyx layer was reported to correlate with the severity of the disease and increased levels of hyaluronan was reported to be associated with endothelial barrier dysfunction. ${ }^{22}$

Irrespective of whether the etiology is related to infection-associated inflammation or a direct entry of the virus into the vascular endothelial cells, data from the current study suggests that COVID-19 can lead to a reduction in VD of retinal capillary plexus, even when the disease is mild or asymptomatic. Studies with longer follow up time are needed to confirm whether this reduction in VD is irreversible or not.

\section{Declarations \\ Funding Acknowledgements:}

This research received no specific grant from any funding agency in the public, commercial, or not-for-profit sectors.

\section{Declaration of conflicting interests:}

The authors report there are no competing interests to declare.

\section{References}

1. Zhou F, Yu T, Du R, Fan G, Liu Y, Liu Z, Xiang J, Wang Y et al "Clinical course and risk factors for mortality of adult inpatients with COVID-19 in Wuhan, China: a retrospective cohort study”. Lancet 2020 Mar 28;395(10229):1054-1062.doi: 10.1016/S0140-6736(20)30566-3

2. Giannis D, Ziogas IA, Gianni P "Coagulation disorders in coronavirus infected patients: COVID-19, SARSCoV-1, MERS-CoV and lessons from the past". J Clin Virol 2020 Jun;127:104362. doi: 10.1016/j.jcv.2020.104362

3. Venkatesh R, Reddy NG, Agrawal S, Pereira A (2021) “COVID-19-associated central retinal vein occlusion treated with oral aspirin”. BMJ Case Rep ;14:e242987. doi:10.1136/bcr-2021-242987

4. Finn AP, Khurana RN, Chang LK (2021) “Hemi-retinal vein occlusion in a young patient with COVID-19”. Am J Ophthalmol Case Rep Jun;22:101046

5. Gaba WH, Ahmed D, Al Nuaimi RK, Al Dhahani AA, Eatmadi A (2020) "Bilateral Central Retinal Vein Occlusion in a 40-Year-Old Man with Severe Coronavirus Disease 2019 (COVID-19) Pneumonia”. Am J Case Rep, ; 21: e927691

6. Bapaye MM, Nair AG, Bapaye CM, Bapaye MM, Shukla JJ "Simultaneous Bilateral Central Retinal Artery Occlusion following COVID-19 Infection”. Ocul Immunol Inflamm 2021 Apr 15;1-4. doi: 10.1080/09273948.2021.1891262

7. Benito N, Filella D, Mateo J et al (2020) “Pulmonary Thrombosis or embolism in a large cohort of hospitalized patients with Covid-19". Front Med 2020 7:557. https:// doi. org/ 10. 3389/ fmed. 00557

8. Al-Ani F, Chehade S, Lazo-Langner A (2020) “Thrombosis risk associated with COVID-19 infection A scoping review”. Thromb Res 2020 192:152-160. https:// doi. org/ 10. 1016/j. throm res. 05. 039

9. Costa IF, Bonifacio LP, Bellisimo-Rodrigues F, Rocha EM, Jorge R, Bollela VR, Antunes-Foschini R (2021) "Ocular findings among patients surviving COVID-19". Sci Rep. ; 11: 11085

10. Bypareddy R, Rathod BLS, Shilpa YD, Hithatshree HR, Nagaraj KB, Hermalatha BC et al (2021 May) "Fundus evaluation in COVID-19 positives with nonsevere disease". Indian J Ophthalmol. ; 69(5): 1271-1274

11. Zago Filho LA, Lima LH, Melo GB, Zett C, Farah ME (2020) Vitritis and outer retinal abnormalities in a patient with COVID-19. Ocul. Immunol. Inflamm. 28, $1298-1300$

12. Guemez-Villahoz N, Burgos-Blasco B, Vidal-Villegas B, Donate-Lopez J, Herrera de la Muela M, Lopez-Guajardo L, Martin-Sanchez FJ, Garcia-Feijoo J "Reduced macular vessel density in COVID-19 patients with and without associated thrombotic events using optical coherence tomography angiography”. Graefes Arch Clin Exp Ophthalmol 2021 May 7;1-7. doi: 10.1007/s00417-021-05186-0

13. Turker IC, Uslu Dogan C, Guven D, Kutucu OK (2021 Apr;56(2):83-87) “Optical coherence tomography angiography findings in patients with COVID-19”. Can J Ophthalmol. doi: 10.1016/j.jcjo.2020.12.021 
14. Cennamo G, Reivaldi M, Montorio D, D’Andera D, Fallico M, Triassi M (2021 Jul;227:182-190) “Optical Coherence Tomography Angiography Features in Post-COVID-19 Pneumonia Patients: A Pilot Study." Am J Ophthalmol doi: 10.1016/j.ajo.2021.03.015

15. Lavia C, Mece P, Marco N, Bonnin S, Marie-Louisse J, Couturier A, Erginay A, Tadayoni R, Gaudric A (2020) "Retinal Capillary Plexus Pattern and Density from Fovea to Periphery Measured in Healthy Eyes with Swept-Source Optical Coherence Tomography Angiography”. Sci Rep. 10:1474 https://doi.org/10.1038/s41598-020-58359-y

16. Hirano T, Chanwimol K, Weichsel J, Tepelus T, Sadda S (2018) “Distinct Retinal Capillary Plexuses in Normal Eyes as Observed in Optical Coherence Tomography Angiography Axial Profile Analysis" Sci Rep 8:9380 doi:10.1038/s41598-018-27536-5

17. Ganier C, Du-Harpur X, Harun N, Wan B, Arthurs C, Luscombe N et al CD147 (BSG) But Not ACE2 Expression Is Detectable in Vascular Endothelial Cells Within Single Cell RNA Sequencing Datasets Derived From Multiple Tissues in Healthy Individuals. bioRxiv. 2020, 2020.05.29.123513. doi: $10.1101 / 2020.05 .29 .123513$

18. Nascimento Conde J, Schutt WR, Gorbunova EE, Mackow ER (2020) Recombinant ACE2 Expression Is Required for SARS-CoV-2 To Infect Primary Human Endothelial Cells and Induce Inflammatory and Procoagulative Response. mBio 1, e03185-20. doi: 10.1128/mBio. 03185-20

19. Fox SE, Akmatbekov A, Harbert JL, Li G, Brown Q, Heide V (2020) Pulmonary and Cardiac Pathology in African American Patients With COVID-19: An Autopsy Series From New Orlean. Lancet Respir Med 8, 681-686. doi: 10.1016/S2213-2600(20)30243-5

20. Goshua G, Pine AB, Meizlish ML, Chang CH, Zhang H, Bahel P et al (2020) Endotheliopathy in COVID-19-Associated Coagulopathy: Evidence From a Single-Centre, Cross-Sectional Study. Lancet Haematol 7, e575-e582. doi: 10.1016/S2352-3026(20)30216-7

21. Liu F, Han K, Blair R, Kenst K, Qin Z, Upcin B, Wörsdörfer P, Midkiff CC, Mudd J, Belyaeva E, Milligan NS, Rorison TD, Wagner N, Bodem J, Dölken L, Aktas BH, Vander Heide RS, Yin XM, Kolls JK, Roy CJ, Rappaport J, Ergün S, Qin X SARS-CoV-2 Infects Endothelial Cells In Vivo and In Vitro. Front Cell Infect Microbiol. 2021 Jul 6;11:701278. doi: 10.3389/fcimb.2021.701278

22. Queisser KA, Mellema RA, Middleton EA, Portier I, Manne BK, Denorme F, Beswick EJ, Rondina MT, Campbell RA, Petrey AC COVID-19 generates hyaluronan fragments that directly induce endothelial barrier dysfunction JCl Insight 2021 Jul 27;147472. doi: 10.1172/jci.insight.147472 